\title{
Integration of Manufacturing into Mechanical Engineering Education Cur- ricula
}

\section{Prof. Robert L. Mott, University of Dayton}

Robert L. Mott, P.E. is professor emeritus of engineering technology at the University of Dayton. He is a member of ASME, SME, and ASEE. He is a Fellow of ASEE. He holds the Bachelor of Mechanical Engineering degree from General Motors Institute (Now Kettering University) and the Master of Science in Mechanical Engineering from Purdue University. He serves the Society of Manufacturing Engineers through the Manufacturing Education \& Research Community and the SME Center for Education and he is a recipient of the SME Education Award. He has authored four textbooks. Applied Fluid Mechanics 7th ed, Applied Strength of Materials 5th ed, Statics and Strength of Materials, 1st ed, and Machine Elements in Mechanical Design 5rd ed, all published by Pearson/Prentice-Hall.

\section{Dr. Ronald J. Bennett, University of St. Thomas}

Dr. Ronald J. Bennett is Founding Dean and Professor Emeritus of the School of Engineering at the University of St. Thomas. Prior to entering academia, Bennett held leadership positions for three decades in the appliance, electronics, medical device and knowledge engineering industries, as well as in several entrepreneurial organizations. His responsibilities ranged from R\&D, engineering and manufacturing to sales, marketing and general management.

He founded the School of Engineering at the University of St. Thomas, and teaches and publishes in the areas of materials engineering, innovation, strategy, technology transfer, leadership and engineering education. His current focus is on webinars and workshops on leadership for engineers in industry and academia.

Bennett is a member of numerous scientific and professional societies, is an ABET program evaluator and commissioner.

He has a wide variety of academic publications, and is co-author with Elaine Millam of the 2012 McGrawHill book 'Leadership for Engineers: The Magic of Mindset.'

\section{Mr. Mark J. Stratton, SME (Society of Manufacturing Engineers)}

Dr. Scott Danielson, Arizona State University, Polytechnic campus

Dr. Scott Danielson is the Associate Dean for Academic Programs in the College of Technology and Innovation at Arizona State University's Polytechnic campus. Before assuming that role, he had been the Interim Chair of Engineering Department for half a year and the Chair of the Engineering Technology Department for over 12 years. He has been active in the ASEE in the Mechanics Division and the Engineering Technology Division, currently a member at large on the Engineering Technology Division Executive Committee. He serves on the SME's Manufacturing Education and Research Community steering committee. He is active in the ASME; awarded the Ben C. Sparks Medal in 2009 and 2013 for excellence in mechanical engineering education, serving as a member of the Vision 2030 Task Force, serving on the Committee on Engineering Technology Accreditation in a variety of roles, serving on the Board of Directors of the ASME Center for Education for several years, and as a member of the Mechanical Engineering Technology Department Head Committee. He has been a program evaluator for both the Society of Manufacturing Engineers (SME) and ASME, served on the Engineering Technology Accreditation Council (ETAC) of ABET, representing ASME, and currently is on the ETAC Executive Committee. Before joining ASU, he had been at North Dakota State University where he was a faculty member in the Industrial and Manufacturing Engineering department. His research interests include machining, effective teaching and engineering mechanics. Before coming to academia, he was a design engineer, maintenance supervisor, and plant engineer. He is a registered professional engineer. 


\title{
INTEGRATION OF MANUFACTURING INTO MECHANICAL ENGINEERING CURRICULA
}

\begin{abstract}
This paper focuses on enhancing the integration of manufacturing principles and concepts within curricula in mechanical engineering and mechanical engineering technology education programs. The field of manufacturing engineering covers the broad spectrum of topics derived from the definition, "Manufacturing requires that a modification of the shape, form, or properties of a material that takes place in a way that adds value"1. The ASME's Vision 2030 surveys of industry engineering supervisors and early career mechanical engineers have illustrated that the curricula of mechanical engineering and related programs have an urgent need to enhance students' comprehension of 'how things are made and work,' e.g., the knowledge and skills needed to design and efficiently produce products via high-performance systems. ${ }^{2}$ This paper focuses primarily on a model for the manufacturing field called The Four Pillars of Manufacturing Knowledge, developed by the Society of Manufacturing Engineers, and how it can inform and guide mechanical engineering education. ${ }^{3}$ Broader issues and resources related to enhancing manufacturing education are also presented.
\end{abstract}

\section{Introduction}

Manufacturing is experiencing a resurgence of interest in the American consciousness and the choice of the theme, Advanced Manufacturing, for the ASME 2013 International Mechanical Engineering Congress and Exposition (IMECE) is strongly aligned with this resurgence and the increasing U.S. investment in manufacturing innovation, research, and education. The ASME's Vision 2030 surveys of industry engineering supervisors and early career mechanical engineers have illustrated that the curricula of mechanical engineering and related programs have an urgent need to enhance students' comprehension of 'how things are made and work,' e.g., the knowledge and skills needed to design and efficiently produce products via high-performance systems. $^{2}$

A stated objective of the IMECE's Advanced Manufacturing theme is to "increase cooperation across multiple disciplines." This paper attempts to foster such cooperation and illustrate the span of topics related to manufacturing that would enhance mechanical engineering education as related to advanced manufacturing. Enhancing manufacturing content is doubly important as a large percentage of graduates from mechanical engineering education programs enter careers within the manufacturing engineering function of product producing industries.

This paper focuses on enhancing the integration of manufacturing principles and concepts within curricula in mechanical engineering and mechanical engineering technology programs. The field of manufacturing engineering covers the broad spectrum of topics derived from the definition, "Manufacturing requires that a modification of the shape, form, or properties of a material that takes place in a way that adds value", 
Certainly, many topics currently covered well in mechanical engineering education curricula are part of the body of knowledge for manufacturing engineering, such as materials engineering, product design, engineering sciences, and control systems. Some programs include instruction in manufacturing processes. However, as shown by the Vision 2030 survey data, industry sees the mechanical engineering graduates as weak in understanding of how things are made, i.e., manufacturing. So, this paper can help mechanical engineering educators see how to strengthen their programs by using the Four Pillars framework to raise the awareness of the breadth of the manufacturing field, complementing the excellent education already provided by mechanical engineering education programs. Specific suggestions are made to guide programs as they work to address the weakness illustrated by the Vision 2030 data.

\section{The ASME Vision 2030 Study and its Relation to this Paper}

Starting in 2008, the ASME Vision 2030 Task Force investigated the current state of mechanical engineering education and practice within industry. In addition to an engineering education literature review, extensive surveys of three key stakeholder groups (mechanical engineering and mechanical engineering technology department heads, industry supervisors and early career engineers) were conducted to assess the strengths and weaknesses of mechanical engineering education graduates. Responses were received from academic leaders at more than 80 institutions, from more than 1,400 engineering managers, and more than 600 early career engineers (those with less than ten years of practice). These survey responses were shown to be statistically valid and resulting data provide a groundbreaking view of mechanical engineering education.

In a broad-brush summary of the Vision 2030 survey data, the industry supervisors' four greatest perceptions of weakness are worth highlighting. These four were focused on engineering practice - how devices are made and how they work, communication within diverse engineering teams and with stakeholders in the organization, engineering codes and standards, and a systems perspective. Notably, early career engineers judged their greatest weaknesses as practical experience, project management, knowledge of business processes and engineering codes and standards. $^{2}$ Many of these perceptions of weakness point unmistakably to a lack of emphasis on translating mechanical engineering coursework and knowledge to everyday practice. Critical aspects of understanding the needed changes to mechanical engineering curricula are based on how things are made and work via increased, practical knowledge of manufacturing processes, and how materials are impacted by those processes.

The Vision 2030 group notes that employment in the U.S. can only increase if its engineers design and build more globally competitive products, whether "high-tech" or not. In other words, America's return to a position of strength in world-class product development and manufacturing requires that mechanical engineering education students be better prepared. Clearly, manufacturing engineering topics are important to mechanical engineering programs.

Six aspects of the mechanical engineering educational landscape emerged as target areas for change. They encompass a wide range, spanning the educational pathways of mechanical engineering and mechanical engineering technology. Vision 2030 findings are focused on six major areas of curricular change: creating curricula that inspire innovation and creativity, increasing curricular flexibility, offering more authentic practice-based engineering experiences, 
developing students' professional skills to a higher standard, attracting a more diverse student body and developing increased faculty expertise in professional practice. All of these have a direct connection to the inclusion of manufacturing knowledge within mechanical engineering education curricula. They clearly link the structure and intent of the SME Four Pillars of Manufacturing Knowledge to the educational goals of preparing mechanical and manufacturing engineers for industry. The Four Pillars of Manufacturing Knowledge (Figure 1) provides illumination and guidance as to how such inclusion can be accomplished and the critical topics to be addressed. Sections 3 and 4 that follow expand on the nature of the Four Pillars model and how it can aid the implementation of curriculum adjustments with more manufacturing content.

\section{Overview of the Manufacturing Engineering Field}

The manufacturing engineering field covers the broad spectrum of engineering and technology concepts, knowledge areas, skills, and abilities that affect the planning, implementation, operation, continuous improvement, and management of the industrial functions required to develop, produce, and improve products of all kinds. The practical design and implementation of manufacturing systems includes the integration of materials science, materials processing, engineering sciences, product design, and process design along with the operational aspects of manufacturing, supporting the premise of the importance of manufacturing to mechanical engineering curricula.

Recent work by the Society of Manufacturing Engineers through its Center for Education and the Manufacturing Education and Research community have consolidated this work and created a concise, graphical representation of the manufacturing field-the Four Pillars of Manufacturing Knowledge as shown in Figure 1. ${ }^{3}$

The Four Pillars of Manufacturing Knowledge essentially differentiates the unique character of manufacturing, manufacturing engineering and manufacturing engineering technology, defines the standard for advanced manufacturing topics, and provides a body of knowledge with which all those engaged in advanced manufacturing education can align. Developed by the Society of Manufacturing Engineers (SME) through its Center for Education, the four pillars are derived from the ABET accreditation criteria for manufacturing engineering programs and build on the topics in the SME-defined "Body of Knowledge for the Certification of Manufacturing Engineers and Manufacturing Technologists." It is a tool for promoting greater understanding of the breadth and depth of the field of manufacturing engineering.

Graphic Representation of the Four Pillars of Manufacturing Knowledge To help communicate the Four Pillars model and the attendant details to a wide range of people and organizations, the graphic representation in Figure 1 was developed using the metaphor of a building whose roof structure representing a product-producing industry is supported by four pillars that rest on a foundation.

The foundation shows the educational fundamentals on which the manufacturing engineering field is based, including mathematics and science, communications, and the many aspects of personal effectiveness (what Vision 2030 called professional skills). 


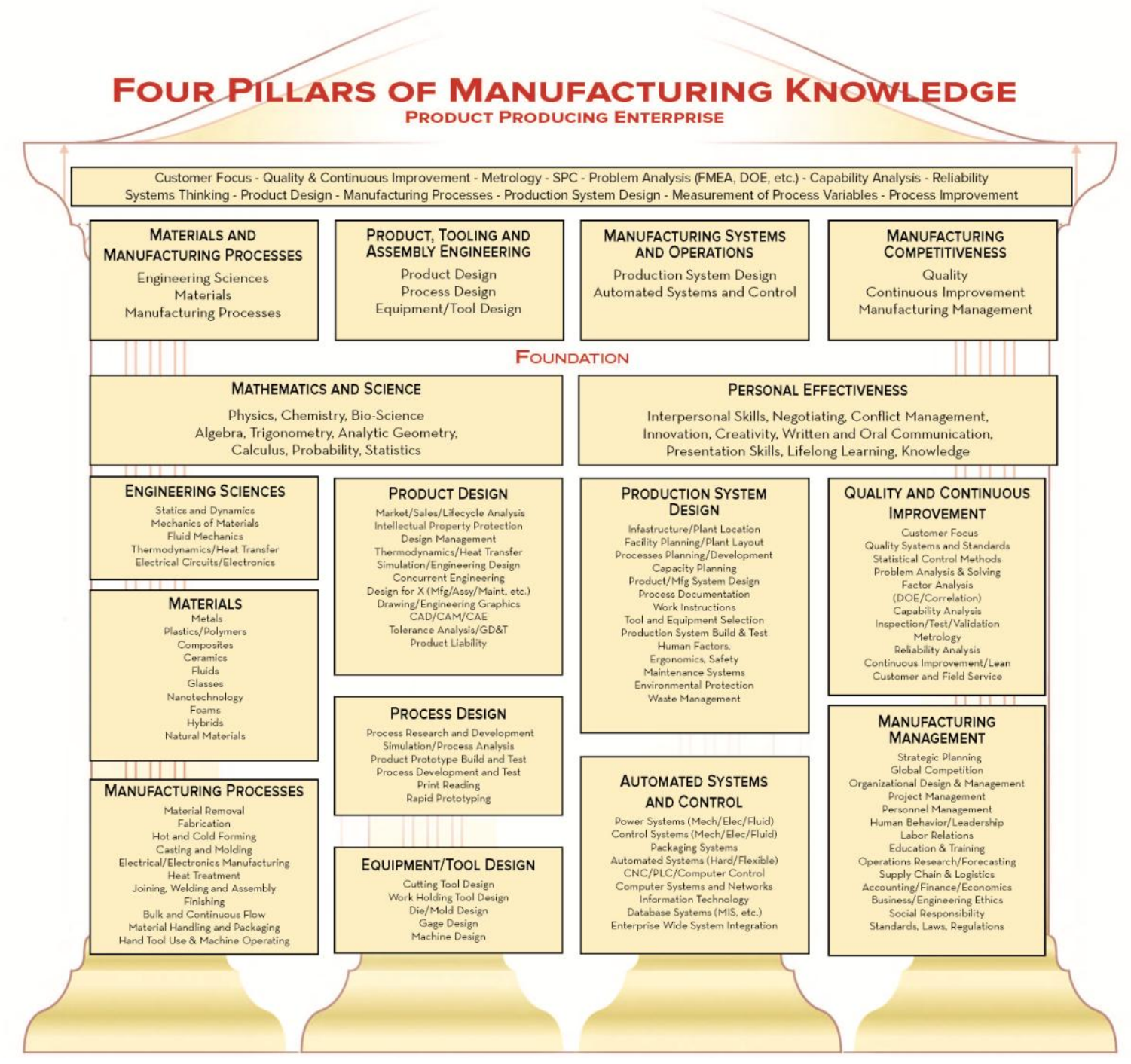

Figure 1 The Four Pillars of Manufacturing Knowledge ${ }^{3}$

The four pillars are capped with the titles shown above for the four major proficiencies expected of graduates of manufacturing programs. The four pillars are identified as:

- Materials and manufacturing processes: understanding the behavior and properties of materials as they are altered and influenced by processing in manufacturing,

- Product, tooling, and assembly engineering: understanding the design of products and the equipment, tooling, and environment necessary for their manufacture,

- Manufacturing systems and operations: understanding the creation of competitive advantage through manufacturing planning, strategy, and control, and

- Manufacturing competitiveness: understanding the analysis, synthesis, and control of manufacturing operations using statistical methods, simulation and information technology. 
Below the titles of the major subject areas are ten lists for the detailed topics that make up the content of the programs. The ten major subject areas mentioned earlier are arrayed to give more detail to the content included in baccalaureate degree programs. This list forms the basis for SME certification exams for Certified Manufacturing Engineer and Certified Manufacturing Technologist. $^{4}$

The lintel spanning the pillars emphasizes that laboratory experiences, quality, continuous improvement, and problem analysis pervade the manufacturing engineering field and integrate its various facets. This approach aligns with many of the personal effectiveness techniques.

While there are multiple uses of the Four Pillars of Manufacturing Knowledge, for the purposes of this paper, the focus is on fostering ongoing dialog among faculty in mechanical engineering and mechanical engineering technology programs whose graduates often work in manufacturing engineering functions of product-producing industries. Such dialog will help to ensure that graduates obtain knowledge and skills in critical manufacturing principles and practices.

It is understood that the Four Pillars model must be adapted by each type of educational program and other entities depending on their own purposes, objectives, and goals. Variations naturally exist among associate degree programs, baccalaureate degree programs and graduate programs in terms of breadth and depth to which the concepts incorporated in the Four Pillars model are included in curricula based on the expected career paths of graduates. Programs that do not have "manufacturing" in their names but whose graduates often enter the manufacturing functions of product-producing industries should have some knowledge of the fundamentals of manufacturing as outlined in the Four Pillars model. It is recommended that the Four Pillars model be used by all who design and deliver curricula where graduates move into manufacturing. Some programs may be satisfied with an awareness level of coverage while others may choose to include more depth.

\section{Application of the Four Pillars of Manufacturing Knowledge to Mechanical Engineering and Mechanical Engineering Technology Programs}

Many who work within the manufacturing engineering function come from other disciplines such as mechanical engineering, electrical engineering, materials engineering, industrial engineering and others. It seems appropriate that all professional employees engaged in manufacturing engineering have an awareness of the breadth of the manufacturing engineering field along with depth in certain parts of the total spectrum of manufacturing topics.

It is well recognized that mechanical engineering education curricula have a long history of success in meeting the needs of many career paths. Some mechanical programs, especially those in mechanical engineering technology, also include significant content in manufacturing, although the Vision 2030 study indicates that this segment needs to be enhanced, particularly in mechanical engineering programs. There is significant overlap between mechanical and manufacturing engineering education curricula, particularly in regard to mathematics, engineering sciences, materials science, engineering drawing/CAD, and others. Also, many mechanical and manufacturing education curricula include aspects of manufacturing processes, product design principles, and equipment design, although often with different emphases. 
The following are examples of how the Four Pillars model can be used to enhance the design/build stem of mechanical curricula.

- Use the Four Pillars of Manufacturing Knowledge as a basis for providing students an awareness level of the breadth of the manufacturing field in which many of them will find productive careers. Figure 1 is a tool that can help to accomplish that.

- When teaching core ME courses, examples of how the competencies being learned apply in a manufacturing application should be discussed. Examples include: statics, dynamics, mechanics of materials, fluid mechanics, thermodynamics, and heat transfer.

- Critical areas from the manufacturing knowledge base that all mechanical engineering education programs should strongly consider including in their curricula are: the impact of processing on materials, especially from the vantage point of materials selection, basic manufacturing processes (with laboratory), metrology with linkages to geometric dimensioning and tolerancing (GD\&T), and statistical quality control.

- When teaching product design, ensure that principles of simultaneous product and process design are emphasized, continuously envisioning how a component or assembly can be manufactured with high quality and reasonable cost, in addition to ensuring that it performs at a desired level. Using the concepts from the product realization process (PRP), design for X (manufacturability, assembly, maintenance, service, disposal, etc), materials selection, tolerance analysis and geometric dimensioning and tolerancing (GD\&T) would enhance mechanical engineering graduates' understanding of how things are made.

- When performing materials selection for product components, consider the types of manufacturing processes which are appropriate for fabricating or forming the components, along with the traditional properties of strength, stiffness, fracture toughness and so forth. Use of materials selection software can facilitate this approach. One such software product is called CES EduPack, developed and distributed by Granta Design using methodologies conceived by Professor Michael F. Ashby of Cambridge University in Cambridge UK. Another useful tool is the book, Materials Selection in Mechanical Design, authored by Professor Ashby and published by Elsevier - Butterworth Heinemann.

- When students gain experience in design processes, they should recognize the complexity of the total production process, not only product and process design, but production system design, automation systems and controls, quality and continuous improvement methods, problem solving and decision making, supply chain management and management of the entire product-producing enterprise.

- Educators should emphasize that products are often designed and manufactured by the same organization or in a coordinated fashion. Design work can illustrate the feedback of manufacturing detail to influence the continuous improvement of the product. Students will learn that difficulties encountered in manufacturing, or in the final use environment, can be corrected by the design and manufacturing engineers, at reasonable cost, and in a coordinated fashion. Finding those difficulties earlier in the design process reduces overall costs and decreases time to production and to the market. 
- Students should be taught to minimize the environmental costs associated with the product and its manufacture, using the principles of product life-cycle costing and management.

These examples were identified by using the Four Pillars of Manufacturing Knowledge model to align the skills and knowledge learned in typical mechanical engineering and engineering technology education programs with the complete matrix of concepts shown in the model. Accomplishing these goals can be integrated within existing courses, not by having numerous new courses.

An example of the successful implementation of manufacturing within a bachelor's degree mechanical engineering technology program is described in the paper by Georgeou and Danielson. 5

The authors of this paper were not able to obtain detailed information about specific mechanical engineering education programs that include strong manufacturing content. Readers who may know of such programs are encouraged to contact the authors with that information.

The Four Pillars of Manufacturing Knowledge can also be used to guide community colleges, whether fielding an accredited program or not, as to important content to include in their technical or manufacturing-related degrees. The workforce of the future increasingly will need the education and training provided at the sub-baccalaureate level to enter a field, and in some cases to maintain job tenure. Approximately $43 \%$ of all undergraduates are in community colleges, including the plurality of minority students and the majority of low-income students. Community colleges serve as a launching pad for greater educational attainment and related

benefits of social mobility and economic security. ${ }^{6}$ The type of qualified workers that are produced by these programs include production associates, machinists, operators, a variety of manufacturing-related craft workers, distributors and technicians. All of these programs can benefit by utilizing the Four Pillars model as they undertake programmatic continuous improvement. Community colleges also often deliver early parts of mechanical engineering or mechanical engineering technology curricula and should seek to enhance the manufacturing content of such courses.

\section{Competitiveness Issues Related to Design and Manufacturing Decisions}

In addition to the relationship of manufacturing to mechanical engineering and mechanical engineering technology mentioned earlier, there is a particularly important role for design considerations related to materials and process selection in manufacturing competitiveness. There is an obvious relationship between the properties required in the final product and the properties of the materials that make up the product. However, there often are many materials that will result in the required properties. As design engineers, we frequently chose materials and processes with which we are most familiar, and tend to neglect those with which we are less familiar, but which may offer a strong competitive advantage in a variety of ways, from initial material cost, to manufacturability, to the ultimate reuse or recycling of the material and the total life cycle cost and impact.

Einstein is credited with a statement to the effect that ' $90 \%$ of solution to a problem lies in correctly framing it in the first place'. The issues of quality of the product/process relates to this. 
If we don't have time to do it right in the first place, how can we find time to fix it later? This gets to the notions of strategic planning, reliability and waste management. Without adequate attention to systems planning, the result is a series of engineering change orders (ECOs) that do not add value, but merely raise cost and delay introduction of the product.

Choices made early in the design cycle, while not incurring immediate significant expense, lock in the future costs associated with procurement of materials, supply chain costs, manufacturing processes, decisions about making vs. buying, and more. Specifying unnecessary properties or constraints merely drive up cost and delay supply without adding value. Specifying particular materials affects the make/buy decision, and may dictate the need to outsource vs. make in one's own factory. Materials selection also establishes the processes, and post-processes, required to develop the final desired properties. Paying particular attention to options of materials/processes early in the design phase can greatly reduce cost and delay in product introduction.

The prediction of product volume, a strategic decision, can also have a significant effect on ultimate material/manufacturing costs. Some processes have high initial tooling cost with low unit production cost; other have low tooling cost, but higher unit production cost. Knowledge of both materials and manufacturing methods, combined with accurate estimates of product volumes, determine the profitability of the end product.

There is also the issue of ethics. Selection decisions for materials and processes have a dramatic impact on environmental protection, waste management, engineering ethics and social responsibility. The 'Obligation of the Engineer', promulgated by the National Society of Professional Engineers (NSPE), requires that engineers 'conserve nature's resources'. This is an obligation that engineers of all disciplines, and particularly design engineers and manufacturing engineers, should consider in any professional decision. See the following website. (http://www.nspe.org/PEmagazine/pe_0709_Called.html?printerFriendly=true)

There are a number of ABET student outcome requirements that relate to the issue of design and manufacturing, particularly in the capstone design criteria. Among those outcomes is (Criterion 3(c)) 'the ability to design a system, component, or process to meet desired needs within realistic constraints such as economic, environmental, social, political, ethical, health and safety, manufacturability, and sustainability'.

It is therefore important for everyone educated in mechanical engineering to have a working knowledge of manufacturing and all that it entails to be able to make good, professional decisions about design choices and applications.

\section{National Issues Related to Mechanical and Manufacturing Education}

Recent national emphasis and publicity on the importance of manufacturing to the economy of the United States, North America, and the entire world is promising and important for mechanical engineering educators to note.

The 2012 report ${ }^{7}$, “A National Strategic Plan for Advanced Manufacturing” includes five areas of recommendations. Developed by the National Science and Technology Council (part of the Executive Office of the President), it is an innovation policy, not an industrial policy, having cross-cutting breadth of application with the federal role to support infrastructure for partnership 
building to move ideas from research to high levels of technical readiness. Mechanical engineering as a profession has an important role, alongside their manufacturing engineering colleagues, to realize the goals of this strategic plan.

The Advanced Manufacturing Partnership (AMP), [http://www.manufacturing.gov/amp.asp] represents the private sector perspective on manufacturing. These and other such national initiatives indicate that manufacturing is getting a significant amount of positive attention, creating expectations of resources and support for innovation that includes both product design and manufacturing that will have an impact on manufacturing education and research.

Mechanical engineering educators' scholarly activities can take advantage of these initiatives to enhance the funding stream and also to do important work that will enhance the United States' competitive position.

In January 2011, President Barack Obama signed the America COMPETES Reauthorization Act of 2010 (H.R. 5116), legislation aimed at advancing U.S. competitiveness in the critical areas of science, technology, and education. [America COMPETES is a short term for "America Creating

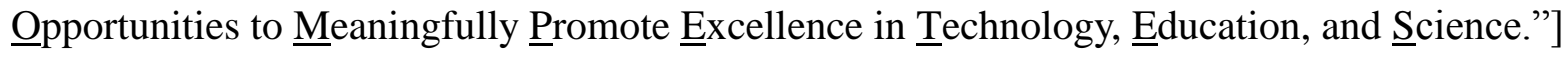
The COMPETES act also calls for NIST to expand upon its work with the private sector to develop standards in support of key manufacturing industries such as:

1. Supporting advanced manufacturing research and development to foster the transfer of results into new manufacturing technologies and United States based manufacturing of new products and processes for the benefit of society to ensure national, energy, and economic security

2. Supporting and strengthening all levels of advanced manufacturing education and training to ensure an adequate, well-trained workforce.

3. Supporting advanced manufacturing development to assist small- and medium-sized manufacturers in developing and implementing new products and processes.

Efforts are underway to seek another reauthorization and updating of the COMPETES act, Again, these activities provide opportunities for mechanical engineering educators and their programs.

\section{Other Resources on Manufacturing Education}

The Society of Manufacturing Engineers has long been at the forefront of supporting manufacturing education and developing the ways and means of continuously improving curricula and methods of delivering quality programs in this field. Some recent publications are listed here that may be useful to mechanical engineering education program planners when considering enhancing manufacturing content:

1. Workforce Imperative: A Manufacturing Education Strategy $\mathbf{8}^{\mathbf{8}}$ A white paper released nationally in 2012 that summarizes the importance of manufacturing in the United States and that presents six recommendations that educators, industry, professional organizations, and government can use to enhance manufacturing education. The Conclusion for this paper offers more discussion of its recommendations.

2. Curricula 2015: A Four Year Strategic Plan for Manufacturing Education" - This extensive, 152-page document was developed in 2011 by the SME Manufacturing Education \& Research community with input from a large number of academic, industry, government, and association professionals over the period from 2008 through 2011. 


\section{Future Directions for the Collaboration between Mechanical Engineering Education and Manufacturing Engineering Education}

Discussions among the ASME Board on Education and the SME Center for Education have identified several areas of potential strategic alignment regarding the recommendations in the SME white paper Workforce Imperative: A Manufacturing Education Strategy ${ }^{8}$ and effective strategic and tactical ways of collaborating are being planned. The following points describe potential areas of alignment, extracted from the March 5, 2013 letter to Dr. Ronald Bennett, leader of the SME Center for Education, from Dr. Mo Hosni, ASME Vice President, Education.

- Efforts to attract more students into manufacturing by promoting the availability of creative, high-tech jobs and giving students a strong STEM foundation. There are many programs attempting to do this, but their efforts are not coordinated. ASME and SME and related engineering programs can focus on the Next Generation Science Teaching Standards (NGSS), teacher awareness and skills development, and near-peer engineering student engagement in pre-college outreach.

- Articulating a standard core of manufacturing knowledge to guide the accreditation of manufacturing programs and certification of individuals. As lead society for manufacturing engineering and manufacturing engineering technology programs of ABET, the program criteria are an SME responsibility. However, since EAC and ETAC function as collective bodies, ASME and SME could work together in deliberating and supporting proposed changes to program and general criteria.

- Improving the consistency and quality of mechanical and manufacturing curricula to better prepare students for manufacturing employment. The Four Pillars of

Manufacturing Knowledge covers the full spectrum of skill and knowledge areas needed by a practicing professional. Further work could be done collaboratively between ASME, based on its Vision 2030 work, and SME on some subset of the model, for example in exploring which advanced technologies and their technical pre-requisites would be important to deploy at both AS and BS levels in both manufacturing and in a design-based mechanical engineering or related curricula.

- Integrating manufacturing topics into STEM education, so that more students are exposed to manufacturing concepts. While some consider 'STEM' education as principally referring to the pre-college level, others see it as more broadly applied. At the heart is the notion that context-based education is a powerful motivator, and technology and engineering applications can be great drivers for interest in science and mathematics. The underlying issue is motivating students to become interested in developing skills that provide the workforce base to enable advanced manufacturing to thrive. There is full agreement among SME and ASME that the educational aspiration is to have truly integrated product and process design and manufacturing, and that a common understanding of manufacturing is an important attribute of future mechanical and other engineers. Collaboration on achieving that vision would be a very positive approach. 
- Developing faculty that can deliver a world-class manufacturing education in spite of a growing number of challenges. There is agreement on a desire to see a greater proportion of mechanical engineering department faculty with significant industry experience, whether through industry supported approaches that result in more Professor of Practice type positions in departments and/or more accessible industry-based, incompany continuing education and also more in-company fellowship experiences for faculty. In addition to these 'major' changes, faculty workshops and webinars are always useful tools for conveying a certain level of knowledge and awareness.

- Strategically deploying existing and new resources into STEM and manufacturing education programs. The existence and core positions of the National Science Teachers Association (NSTA), the International Technology and Engineering Educators Association (ITEEA), and Project Lead The Way (PLTW) are key targets for our energies and resources. The members of these organizations are the key enablers of the pre-college strategy. We have an obvious and key joint collaborative interest in ITEEA and PLTW. Getting the NSTA science teachers to include engineering is somewhat daunting, although models are developing for teaching engineering to K-12 teachers that show promise. See Reference 10. Getting engineering and manufacturing into the conversation and standards is a necessary pre-requisite. See Reference 11.

There is much to be gained by collaboration between ASME and SME in pursuing these common goals. This is an opportunity that must be seized.

\section{Global Initiatives Related to Manufacturing and Mechanical Engineering Education}

In Japan, numerous Kosetsushi Centers provide assistance to Japanese industries and, in turn, engage Japanese universities in that process. They provide both manufacturing research and development, along with enterprise aid programs. Much of the work of the Kosetsushi Centers facilitates two-way dialog between industry and academia with the result that many undergraduate and graduate programs have strong content in manufacturing. ${ }^{13}$

An earlier innovation introducing students to design and manufacturing issues associated with global product realization was the objective of a graduate course introduced in 2004 at Brigham Young University in Utah. It features case studies on globalization issues, technology literature research, team projects and exercises, and international industry visits. Students are expected to complete a product research report, a company research report, and do individual research on a topic to better understand design, manufacturing, and engineering capabilities and issues in difference countries. ${ }^{14}$

\section{Conclusion}

This paper describes the interconnectedness between manufacturing engineering education and mechanical engineering education. It is deemed important to continue to develop this relationship to include a wide variety of constituencies, including the engineering, engineering technology, and industry communities. Expected uses of the Four Pillars of Manufacturing Knowledge model are described, including creating a unified framework for manufacturing content within mechanical engineering education curricula. It has also been useful in this paper to elucidate the 
relationships between mechanical engineering education and manufacturing engineering education.

It is expected that this paper will result in better understanding of the needs for qualified employees at all levels in advanced manufacturing industries with emphasis on the following.

1. Students. More students are needed in mechanical engineering education with a more comprehensive understanding of the full spectrum of topics that make up the manufacturing engineering field.

2. Standards. The Four Pillars of Manufacturing Knowledge model can help to define and promulgate standards for a common understanding of manufacturing content, competencies and credentials for a variety of program types.

3. Consistency and Quality. Programs using the Four Pillars model will clarify the image of advanced manufacturing, offer more consistent and higher-quality curricula, and provide education that meets the needs of manufacturers. These revised curricula will also promote industry recognition.

4. Integration. This paper has focused primarily on linkages between the mechanical engineering education and manufacturing engineering education communities. Similar linkages are being sought with other organizations with a goal of promoting dialog among the several disciplines whose graduates enter the manufacturing supply chain. Also, initiatives to integrate mechanical and manufacturing concepts into STEM education in the K-12 years are needed.

5. Faculty. Development of faculty prepared to teach advanced manufacturing concepts is needed at all levels, from K-12, certificate, and post-secondary programs.

6. Resources. Strategically deploying resources to accomplish these goals is critical. There is a need for widespread collaboration and dialog to support this goal.

\section{References}

1. ABET, Inc. (2010). "Accreditation Standards and Program Criteria for Manufacturing Engineering and Similarly Named Programs." Washington, D.C.:ABET, Inc. [Available for download at http://abet.org/engineering-criteria-2012-2013/]

2. Danielson, S., Kirkpatrick, A., \& Ervin, E. (2011). “ASME Vision 2030: Helping to Inform Engineering Education." In the Frontiers in Education Conference Proceedings, IEEE/ASEE, October 12 - 15, 2011, Rapid City, SD.

OR

ASME. Found at http://www.asme.org/groups/centers-committees/public-affairs-and-outreach/aboutengineering-education. Accessed 4-9-2013.

3. Society of Manufacturing Engineers. (2011a). "Four Pillars of Manufacturing Knowledge.” Dearborn, MI: Society of Manufacturing Engineers. [Available for download at http://www.sme.org/fourpillars]

4. Society of Manufacturing Engineers. (2010). "Certified Manufacturing Technologist and Certified Manufacturing Engineer - Body of Knowledge”, Dearborn, MI: Society of Manufacturing Engineers. [Available for download at http://www.sme.org ] 
5. Georgeou, T. and Danielson, S. (2008). "CNC Machining: A Value-Added Component of Mechanical Engineering Technology Education." Proceedings of the 2008 Annual Conference of the American Society for Engineering Education, June 22-25, 2008, in Pittsburgh, PA.

6. Mullin, C. M. and Phillippe, K. (2013). "Community College Contributions (Policy Brief 2013-01PB)." Washington, D.C.: American Association of Community Colleges. (Available for download at http://www.aacc.nche.edu/Publications/Briefs/Documents/2013PB_01.pdf)

7. National Science and Technology Council. (2012). "A National Strategic Plan for Advanced Manufacturing”, Office of the President, Washington, D.C., February 2012.[Available for download at http://www.whitehouse.gov/sites/default/files/microsites/ostp/iam_advancedmanufacturing_strategicplan_201 2.pdf ]

8. Society of Manufacturing Engineers. (2012). "Workforce Imperative - A Manufacturing Education Strategy", Dearborn, MI: Society of Manufacturing Engineers. [Available for download at http://sme.org/workforceimperative]

9. Society of Manufacturing Engineers. (2011b). "Curricula 2015 - A Four Year Strategic Plan for Manufacturing Education.” Dearborn, MI: Society of Manufacturing Engineers. [Available for download by SME members at the i.sme.org web page]

10. Center for Pre-Collegiate Engineering Education (CPCEE), School of Engineering, University of St. Thomas. (2012). http://www.stthomas.edu/cpcee/

11. Minnesota Science and Engineering Standards. (2012) http://education.state.mn.us/mdeprod/idcplg?IdcService=GET FILE \&dDocName $=005263 \&$ RevisionSelectio nMethod=latestReleased $\&$ Rendition=primary

12. Fraunhofer-Gesellschaft. (2013). "We Forge the Future." http://www.fraunhofer.de/en/aboutfraunhofer.html.

13. U.S. Department of Commerce. (2009). “Japan’s Manufacturing Competitiveness Strategy: Challenges for Japan, Opportunities for the United States.” U.S. Department of Commerce, International Trade Administration, J. Corwin and R. Puckett, 2009.

14. Todd, R.H., Magleby, S. P., and Parkinson, A. R. (2005). "Experiences and Observations in Introducing Students to Design and Manufacturing Globalization." Journal of Manufacturing Systems, Vol. 24/No. 3, 162170 . 